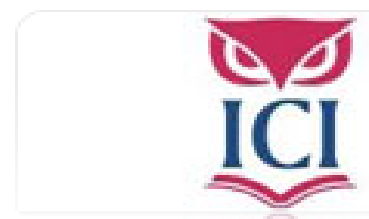

IUS. Revista del Instituto de Ciencias Jurídicas de Puebla A.C.

ISSN: 1870-2147

revista.ius@hotmail.com

Instituto de Ciencias Jurídicas de Puebla A. C.

México

Talavera, Pedro

El desafío pluricultural en el estado nacional

IUS. Revista del Instituto de Ciencias Jurídicas de Puebla A.C., núm. 22, 2008, pp. 134-158

Instituto de Ciencias Jurídicas de Puebla A. C.

Puebla, México 


\section{EL DESAFÍO PLURICULTURAL EN \\ EL ESTADO NACIONAL}

THE CHALLENGE OF PLURICULTURALISM IN THE

NATION-STATE

Pedro Talavera

\section{RESUMEN}

Afrontar el fenómeno de la pluriculturalidad en el seno de los estados-nación, hasta ahora asentados sobre sociedades homogéneas, plantea la necesidad de identificar el doble origen, nacional y étnico, de la pluriculturalidad, de superar la pretendida neutralidad del Estado liberal y reconocer derechos colectivos, aportando soluciones eficaces para encajar el pluralismo moral que la pluriculturalidad comporta. El autor estudia aqui las dos propuestas doctrinales planteadas hasta ahora para la construcción de un nuevo modelo de Estado pluricultural: las que se edifican sobre una ciudadania cosmopolita, y las que lo hacen sobre una ciudadanía diferenciada.

Palabras clave: multiculturalismo, identidad cultural, derechos colectivos, ciudadania

\begin{abstract}
The phenomenon of pluriculturalism within nation-states, untill now based on homogeneous societies, raises the need to identify the double origin, national and ethnical, of pluriculturalism, to overcome the neutrality of liberalism and to recognize collective rights, offering effective solutions to acommodate the moral pluralism that pluriculturalism involves. The author studies here two doctrinal proposals offered for the construction of a new model of pluricultural state: those which are built on a cosmopolitan citizenship, and those which are built on a differentiated citizenship.
\end{abstract}

Key words: multiculturalism, cultural identity, collective rights, citizenship

\footnotetext{
* Profesor titular de filosofía del derecho y filosofía política de la Universidad de Valencia (España). Artículo recibido el 1 de julio de 2008, aceptado el 12 de julio de 2008.
} 


\section{SUMARIO}

1. El estado-nación frente a la pluralidad cultural

2. El doble origen nacional y étnico de la pluriculturalidad

2.1. La plurinacionalidad del Estado

2.2. La polietnicidad del Estado

2.3. La pluriculturalidad frente a la "neutralidad" liberal

3. Identidad, diversidad cultural y derechos colectivos

3.1. La identidad cultural como presupuesto del ejercicio de las libertades

3.2. ¿Cómo encajar el pluralismo moral derivado de la diversidad cultural?

4. Pluriculturalidad y ciudadanía: propuestas de superación del modelo liberal

4.1. Pluriculturalidad y ciudadanía cosmopolita

4.2. Pluriculturalidad y ciudadanía diferenciada

5. Algunas conclusiones

\section{El estado-nación frente a la pluRALIdAd CULtural}

El desbordamiento del fenómeno migratorio ha suscitado en el último cuarto del siglo xx un intenso debate sobre el pluralismo y el multiculturalismo en el seno de los estados-nación, junto a la toma de conciencia de que las sociedades han dejado de ser homogéneas y sobre la necesidad de arbitrar fórmulas para acomodar la diversidad cultural dentro del Estado. Podría decirse que la crisis del estado-nación se ha hecho patente a raíz de la plurietnicidad sobrevenida, pero son las identidades nacionales originarias las que abanderan el tránsito hacia un nuevo modelo de Estado pluricultural (multinacional y poliétnico), basado en un nuevo concepto de ciudadanía (diferenciada), sustentada sobre el reconocimiento de derechos colectivos. Teniendo presente, además, un ulterior reto: la multinacionalidad sobrevenida, esto es, la exigencia de un reconocimiento institucional de grupos nacionales, no originarios, sino constituidos como consecuencia de la inmigración masiva (el caso de la comunidad musulmana es paradigmático en Europa). ${ }^{1}$ En este estudio se analizan las propuestas teóricas planteadas para realizar la transición desde el Estado nacional hacia un nuevo modelo de Estado pluricultural. Cada una de ellas está basada en una nueva concepción de la ciudadanía: la ciudadanía cosmopolita y la ciudadanía diferenciada.

\footnotetext{
1 Vid. KYMlıckA, w., La política vernácula. Nacionalismo, multiculturalismo y ciudadanía, Paidós, Barcelona, 2003.
} 
El estado-nación moderno, el que surge del paradigma de la revolución francesa y norteamericana, no está concebido propiamente como pluricultural, aunque acoja en su seno la pluralidad. Es decir, acoge la pluralidad cultural en el ámbito privado, pero exige de sus ciudadanos una doble integración, política y étnica, de manera ineludible.

En efecto, la cohesión interna del estado-nación se consigue a través de una cierta uniformidad, especialmente en torno a una lengua (cuyo uso se generaliza en un territorio que se considera propio) y a un relato histórico que toma como "sujeto" al Estado. Éstas (y otras) características culturales permiten hablar de "nación" en torno a la que se genera un sentimiento compartido de pertenencia. Pero se trata de una uniformidad compatible con un relevante grado de pluralidad (en las creencias, en los modos de vida, etc.), que se asume como manifestación legítima de la libertad de los ciudadanos y frente a la cual se observa una teórica "neutralidad", sin potenciar o privilegiar ninguna opción. Sin embargo, esa pluralidad se garantiza sólo en el ámbito privado, protegida por el principio de no discriminación.

Por otro lado, el estado-nación exige a sus miembros una doble integración: les pide una integración politica - "fe constitucional”-, es decir, aceptación de los principios del procedimentalismo democrático y de los derechos humanos, y les pide también una integración nacional, es decir, asunción de los rasgos básicos que definen a la nación -se trata de una cierta integración étnica, en sentido "débil", aceptando amplios márgenes de pluralismo-. ${ }^{2}$

En definitiva, el estado-nación tradicional está concebido para un pluralismo "liberal" tal y como lo concibe Sartori en su ensayo La sociedad multiétnica. ${ }^{3}$ Ese pluralismo liberal difícilmente digiere la pluriculturalidad, en sentido estricto, si por tal debe entenderse el reconocimiento político y jurídico de toda singularidad cultural en el espacio público. Para que esto pueda producirse resulta imprescindible un ensanchamiento del espacio jurídico y político habilitado por el estado-nación. Y ello porque la pluriculturalidad exige institucionalizar la diferencia, dentro de un mismo espacio social, para personas que se identifican con culturas diversas en función de identidades nacionales o étnicas. ${ }^{4}$ De ahí el planteamiento de

\footnotetext{
${ }^{2}$ etXebarRría, x., "Estado pluricultural”, en Glosario para una sociedad intercultural (J. Conill, coord.), Bancaixa, Valencia, 2002, p. 141.

3 SARTORI, G., La sociedad multiétnica, Taurus, Madrid, 2002, pp. 46-58.

${ }^{4}$ LAMO DE ESPINOSA, E., Culturas, estados, ciudadanos, Alianza, Madrid, 1995, p. 18.
} 
un nuevo modelo de Estado superador de las exigencias integradoras del estado-nación y abanderado de una nueva concepción de la ciudadanía. Quienes hablan de "Estado pluricultural", se refieren a la articulación de un nuevo modelo político y organizativo que, acogiendo ciertos modos de diversidad cultural (momento fáctico), pretende atribuirles una dimensión significativa dentro de la propia organización institucional del Estado (momento normativo). ${ }^{5}$ El tránsito teórico hacia ese nuevo modelo de Estado parece plantearse sobre el ineludible marco de los derechos colectivos (o diferenciados), ligados al reconocimiento de las minorías nacionales y su exigencia de autogobierno, y al de las minorías étnicas y los denominados derechos poliétnicos y derechos especiales de representación. ${ }^{6}$

\section{El DOBLE ORIGEN NACIONAL Y ÉTNICO DE LA PLURICULTURALIDAD}

Los fenómenos identitarios son los que más en evidencia ponen las limitaciones del estado-nación frente a los problemas que plantea la acomodación de la pluriculturalidad y la gestión del fenómeno nacionalista. ${ }^{7}$ Precisamente el doble origen, étnico y nacional, de la pluriculturalidad es lo que exige su tratamiento diverso a la hora de articularla en un nuevo proyecto político de Estado. Se trata, como destaca Habermas, de fenómenos distintos que no deben ser confundidos, pero que están emparentados. ${ }^{8}$ En efecto, Kymlicka distingue dos modos fundamentales a través de los cuales la pluriculturalidad se hace presente en un Estado: la plurinacionalidad y la polietnicidad, ambas simultáneamente presentes en casi todos los estados. ${ }^{9}$ Cada una presenta su propia peculiaridad en el tratamiento de

\footnotetext{
${ }^{5}$ ETXeBARrí, x., "Estado pluricultural", op. cit., p. 140.

${ }^{6}$ KYMLıckA, w., Ciudadanía multicultural, Paidós, Barcelona, 1996, pp. 46-55.

${ }^{7}$ Las reivindicaciones identitarias actuales tienen una doble dirección: o bien surgen de los autóctonos frente al establecimiento de extranjeros (nacionalismo reactivo), o bien surgen de las reivindicaciones de grupos que, dentro del Estado al que pertenecen, se sienten frustrados o marginados en alguno de los sectores importantes de la vida pública y, fundamentados en su identidad étnica, representada por los elementos que mejor la simbolizan, como la lengua, la religión o el índice racial, pretenden conseguir lo que estiman su derecho (nacionalismo identitario, en sentido estricto). Si el primero genera, sobre todo, problemas de convivencia para el extranjero (racismo y xenofobia) y puede influir en las políticas de extranjería de los estados, el segundo fenómeno genera graves problemas en la estructura del propio Estado, porque influye de manera determinante en la concepción de la ciudadanía y, en situaciones extremas, puede degenerar en un conflicto armado entre los grupos, como es el caso de musulmanes e hindúes en la India; musulmanes y cristianos en Sudán; tutsis y hutus en Burundi; católicos y protestantes en Irlanda; serbios y kosovares en Europa central o musulmanes y cristianos en el Líbano. Se podrían multiplicar los ejemplos.

${ }^{8}$ HABERMAS, J., Más allá del estado nacional, Trotta, Madrid, 1997, pp. 112-113.

${ }^{9}$ KүмLıскA, w., Ciudadanía multicultural, op. cit., pp. 25-46.
} 
los derechos colectivos y en el tránsito político hacia un auténtico Estado pluricultural; pero su correcta y justa gestión se presenta hoy como un cometido esencial de la democracia. ${ }^{10}$

\subsection{La plurinacionalidad del Estado}

En un primer nivel, la plurinacionalidad se presenta cuando la construcción del Estado nacional no consigue imponer de modo armonioso y generalizado la doble integración que éste exige (política y étnica). Existen poblaciones, territorialmente concentradas, con lenguas y tradiciones vivas, en las cuales una parte importante de esa población no acaba de asumir la doble integración o, en un momento dado, incluso la cuestiona. En esas poblaciones siempre está latente una reivindicación de soberanía nacional frente al estado-nación en el que se encuentran. ${ }^{11}$ Cuando eso sucede de hecho, es decir, cuando en estas poblaciones aparece de modo consistente un "proyecto político" de construcción nacional, nos encontramos con una primera expresión de la pluriculturalidad: el Estado plurinacional, en el que determinados colectivos, con asentamiento histórico en un territorio que perciben como propio, se consideran sujetos de identidades nacionales diferenciadas, cuyo tratamiento institucional excede del modelo de pluralismo liberal, basado en la no discriminación individual, y pretenden ejercitar un derecho colectivo de autodeterminación nacional. ${ }^{12}$

El propio término de Estado plurinacional pone de manifiesto su tensión con el estado-nación, surgido con la pretensión de remitirse a una única identidad nacional en todo el territorio -considerado indivisible

\footnotetext{
${ }^{10}$ HABERMAS, J., La inclusión del otro, Trotta, Madrid, 1999, p. 203.

"La intervención de la OTAN en Kosovo vino a demostrar que la efervescencia independentista había agotado su crédito y que la comunidad internacional había cerrado definitivamente las puertas al reconocimiento de nuevos procesos secesionistas. Esta realidad ha reorientado, en general, la expresión del nacionalismo hacia un nuevo contexto de reivindicación más identitario y político cultural. No obstante, las reivindicaciones de un Estado propio por parte de numerosas comunidades nacionales, lejos de atemperarse se han ido agudizando en los últimos tiempos. Algunos países tienen una equilibrada relación interna entre el Estado y su nación (Dinamarca, Portugal, Grecia, Japón o Suecia, por ejemplo); pero otros arrastran una compleja y tensa dialéctica plurinacional (Italia, España, Francia, Inglaterra, etc.). Cada uno de estos supuestos ofrece una problemática completamente peculiar. Desde los problemas de la regionalización italiana y la Padania del Norte, pasando por la de los de bretones o la de los corsos en Francia, hasta la "devolución” identitaria que está haciendo Tony Blair respecto de Escocia y Gales, la complejidad de la convivencia política de flamencos y valones en Bélgica; la tensión interestatal de los länder alemanes; el catalanismo político de Cataluña; las consultas secesionistas de Québec en Canadá y el separatismo terrorista de ETA en el País Vasco.

${ }^{12}$ etXeBArRí, х., "Estado pluricultural”, op. cit., pp. 142-143; күмlıckA, w., Ciudadanía multicultural, op. cit., pp. 26-41.
} 
desde esa unidad nacional-, que se cimenta sobre una sustancial homogeneidad cultural. ${ }^{13}$ Aceptar, pues, la pluralidad de identidades nacionales (culturales) parece minar una de las bases sobre las que el estado-nación se asienta. ¿Cómo afrontar ese conflicto? Caben tres maneras de hacerlo: afırmar el dominio de la nación mayoritaria sobre las otras (un asimilacionismo que hoy se presenta difícilmente justificable) $;{ }^{14}$ favorecer la secesión de las naciones para que cada una realice el modelo de estado-nación (algo decididamente excluido por la comunidad internacional); o aspirar a un Estado que asuma coherentemente, en el respeto de los derechos de todos, su condición de plurinacional.

Más allá de la complejidad que reviste determinar qué debe considerarse nación y qué derechos deben reconocérsele, la articulación de un Estado plurinacional parece requerir, en opinión de Kymlicka, de dos presupuestos básicos: la determinación de las minorías nacionales bajo el criterio del asentamiento originario en el territorio del Estado (no cabe adjudicar la categoría de minoría nacional a los grupos inmigrados) y el reconocimiento de derechos de autogobierno ligados a la protección "externa" de la identidad cultural diferenciada. ${ }^{15}$

\subsection{La polietnicidad del Estado}

Hay un segundo nivel de pluriculturalidad que se suscita en el Estado nacional a causa del fenómeno inmigratorio; es decir, con la masiva afluencia de "extranjeros", provistos de lengua, costumbres y cultura propias, cuya voluntad de integración o asimilación es escasa, y que puede generar una manifestación “reactiva”, con marcado carácter xenófobo, tendente a enfatizar la identidad del grupo cultural mayoritario (nacionalismo reactivo). ${ }^{16}$

\footnotetext{
${ }^{13}$ FERNÁNDEZ RUIZ-GÁlVEZ, E., Igualdad y derechos humanos, Tecnos, Madrid, 2003, pp. 177-178.

${ }^{14}$ Touraine, A., "Vrais et faux problemes", en Une société fragmentée? Le multiculturalisme en dédet, Michel Wieviorka (dir.), Paris, La Découverte y Syros 1997. Vid. También touraine, A., Pourrons-nous vivre ensemble?, op. cit., pp. 197-201; Igualdad y diversidad. Las nuevas tareas de la democracia,

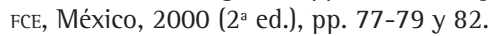

${ }^{15}$ KYмlıска, w., Ciudadanía multicultural, op. cit., pp. 47-52. Mecanismos políticos para atender a las exigencias de autogobierno, ligadas a realidades identitarias de carácter nacional, dentro de un Estado, se han planteado muchas: desde el estado autonómico, hasta el federalismo, sea simétrico o asimétrico, pasando por las confederaciones, las reservas de pueblos indígenas, los protectorados, los estados asociados o los condominios.

${ }^{16}$ El nacionalismo reactivo, suscitado por la inmigración masiva, plantea también una interesante paradoja a la legitimidad esgrimida por el Estado nacional. Tildamos de extranjeros a quienes mantienen su condición de "no nacionales" (por propia voluntad o por imposibilidad) y, por ello, son excluidos de la deliberación y decisión pública y de la distribución equitativa de la riqueza, aunque se acepte su contribución a la producción. Esto plantea ya, como afirma Etxebarría, un grave problema moral a los
} 
Los ejemplos de Francia, Holanda y Alemania vienen siendo frecuentes (obligación de aprender los idiomas nacionales en periodos de tiempo tasados para renovar los permisos de residencia; endurecimiento injustificado de los requisitos para la adquisición de la nacionalidad de las segundas generaciones).

No obstante, cuando hablamos de polietnicidad en un Estado, estamos contemplando la firme voluntad de permanencia y de descendencia de los extranjeros en el país de acogida, de modo tal que ya no se les puede considerar "huéspedes". En efecto, se trata de colectivos significativamente numerosos, agrupados en un mismo territorio, cuya cultura etno-nacional originaria (religión, lengua, instituciones familiares, costumbres, etc.) tiene una marcada diferencia respecto a la cultura de la nación de acogida y con una voluntad explícita de mantenerla (nacionalismo étnico). En estos casos nos encontramos ante una etnicidad "sobrevenida", cuya convivencia en el Estado puede requerir de una peculiar estructura política y organizativa. ${ }^{17}$ La identidad etno-nacional de los inmigrantes puede suscitar un doble problema en la estructura del Estado nacional: a) que esa identidad choque con las exigencias de integración política (derechos humanos y procedimentalismo democrático) que el estado-nación demanda; b) que su voluntad de mantener una cultura propia demande una implicación protectora del Estado respecto a la misma (lengua, tradiciones e instituciones familiares, jurídicas, etc.). ${ }^{18}$

La tensión que la polietnicidad plantea al Estado nacional se ventila en la respuesta que deba darse a esas cuestiones: ¿cabe exigir a los inmigrantes la doble integración política y nacional (cultural), o sólo cabe exigirles

estados. Dado que su legitimidad se construye desde su remisión a los derechos humanos universales, un estado de derecho no puede justificar que un ser humano, precisamente por el hecho de estar en su territorio, no disfrute eficazmente de estos derechos. El que los estados nacionales se constituyan como mediadores en la realización de los derechos humanos pide, por un lado, que éstos sean verdaderos mediadores de cara a sus ciudadanos y, por otro, que no se margine a quienes residiendo en ese Estado no son "nacionales". En coherencia con el principio de legitimidad de los estados, los extranjeros deberían ser reconocidos como sujetos de todos los derechos y deberes de la ciudadanía (ETXEBARRía, x., "Estado pluricultural", op. cit., p. 143).

${ }^{17}$ El mundo está lleno de estas minorías étnicas que, en algunos casos, son fruto inesperado de cambios políticos traumáticos. Por ejemplo, más de dos millones de rusos han visto pasar su condición de etnia dominante a minoría en las tres exrepúblicas bálticas de Estonia, Letonia y Lituania. Es también el caso de tribus y etnias que han sufrido la opresión de los nuevos estados surgidos de la descolonización y reivindican una vuelta a sus viejos nacionalismos fundamentalistas, tal y como surgieron en los orígenes de la lucha por la independencia (África, India, Pakistán, etc., presentan abundantes ejemplos). Pero Europa, en particular, está llena de estos casos: húngaros en Rumania, albaneses en Serbia y Montenegro, serbios en Croacia y Bosnia, turcos en Bulgaria, armenios en Azerbaiyan, polacos en Lituania, uzbekos en Tajikistan, etc.

${ }^{18}$ ETXEBARRí, x., "Estado pluricultural”, op. cit., pp. 143-144. 
la primera de ellas (por remitir a derechos-deberes universales) pero no la segunda, en la que procede reconocer las diferencias identitarias?

Partidario, con matices, de la primera opción es Kymlicka. Parte de la base de que no cabe atribuir a las minorías inmigrantes la categoría de minorias "nacionales", concediéndoles la posibilidad de erigir una cultura separada basada exclusivamente en la peculiaridad de su lengua materna. Afirma que "la expectativa de la integración no es injusta" puesto que la inmigración supone, en cierto modo, una renuncia al derecho de vivir y trabajar en la propia cultura. El desarraigo "voluntario" supone, pues, la renuncia voluntaria a algunos derechos inherentes a la pertenencia nacional original. En todo caso, estima que la expectativa real de los inmigrantes es la integración en la sociedad de acogida. En su opinión, la identidad diferencial de los inmigrantes es perfectamente acomodable dentro del contexto cultural de la sociedad de acogida, de ahí que la integración resulte válida para responder al resurgimiento étnico, si bien esa integración debe tener un sentido bidireccional (desde la sociedad de acogida y desde los inmigrantes). Se trataría, pues, de revisar los términos de la integración de los inmigrantes (derechos poliétnicos: acomodación de calendarios festivos, bilingüismo, uniformidades, etc.), pero no de rechazarla exigiendo derechos nacionales. ${ }^{19}$

Aceptar la segunda hipótesis supondría avalar la articulación de un Estado poliétnico en el que la diversidad cultural expresada por los inmigrantes, no sólo tuviera un reconocimiento diferencial sino nacional, en paridad con las minorías nacionales originarias, que pudiera fundamentar, incluso, derechos de autogobierno. Tal posibilidad, aunque desde el punto de vista teórico no resultara ni incoherente ni injusta -siempre que se dieran las características propias de la identidad nacional- no resulta, sin embargo, realista. Como apunta Kymlicka, hay importantes diferencias entre inmigrantes y colonos. Resulta poco realista la posibilidad de reservar territorios específicos para los inmigrantes de las mismas etnias y carece de sentido apelar al arraigo, cuando la realidad del inmigrante es precisamente la contraria (el desarraigo). ${ }^{20}$

\footnotetext{
${ }^{19}$ KYmLICKA, w., Ciudadania multicultural, op. cit., pp. 135-144. Puesto que para Kymlicka es la voluntariedad de la inmigración lo que justifica la integración, sólo la involuntariedad del desarraigo comportaría una excepción a esa regla general y permitiría la concesión de determinados derechos nacionales. En esta condición particular de involuntariedad se encontrarían los refugiados y habría que considerar el caso de los inmigrantes obligados a desarraigarse por la pobreza, situación a la que no somos ajenos los países ricos de acogida (pp. 139-141).

${ }^{20}$ күмціска, w., Ciudadanía multicultural, op.cit., pp. 135-136.
} 


\subsection{La pluriculturalidad frente a la "neutralidad" liberal}

La respuesta, en el plano teórico, de los estados liberales al desafío de la pluriculturalidad y al reconocimiento de derechos diferenciados es la "neutralidad". Si la exigencia de integración política puede considerarse absoluta e irrenunciable, la "neutralidad" actúa como factor diluyente de la segunda exigencia (integración nacional) y la convierte en matizable y relativa. El principio liberal básico de la no discriminación individual se vería compensado en plano colectivo por la exigencia de igualdad de trato con independencia del grupo cultural al que se pertenezca. La no discriminación entre los grupos vendría garantizada por un igual reconocimiento de las expresiones identitarias (evitando privilegiar o fomentar alguna de ellas), pero excluyendo la aceptación de derechos diferenciados que atentarían al propio principio de igualdad que se pretende garantizar. ${ }^{21}$

Pese a tan pulcro planteamiento, la supuesta neutralidad predicada por el Estado liberal no es en realidad una neutralidad absoluta ni incondicional; es decir, no asume verdaderamente la dimensión pluricultural. En el fondo, como afirma Etxebarría, se trata de una neutralidad “débil”. Por un lado, porque sigue jugando fundamentalmente en el ámbito privado. Por otro lado, porque parte de la preponderancia de las categorias y rasgos básicos de la cultura nacional mayoritaria (lengua, historia, religión, modelo familiar, etc.) y se limita a evitar las desigualdades de trato entre el resto de los grupos. ${ }^{22}$

La pluriculturalidad del Estado pretende superar las insuficiencias de la neutralidad liberal a través del reconocimiento público de derechos diferenciados anexos a la nacionalidad y a la etnicidad, respetando no sólo el principio de no discriminación de los individuos, sino también el de no discriminación entre los grupos. Y ello es así porque, tanto los que constituyen una comunidad nacional como los que proclaman su diferencia étnica, necesitan para la protección de su identidad cultural algo más que el principio liberal de no discriminación personal. Necesitan poder elegir sus opciones, en el contexto de su cultura minoritaria, en igualdad de condiciones con quienes las realizan en el contexto de la mayoritaria. En efecto, los que se consideran minorías nacionales sin Estado, entienden

\footnotetext{
${ }^{21}$ También cabría apelar a la oposición que el reconocimiento de derechos diferenciados supondría frente al planteamiento de la universalidad de los derechos. Una crítica a este supuesta oposición la realiza FERNÁNDEZ RUIZ-GÁlVEZ, E., Igualdad y derechos humanos, op. cit., pp. 180-183.

${ }^{22}$ kYMLıckA, w., Ciudadanía multicultural, op. cit., p. 136.
} 
que hay aspectos fundamentales de su cultura nacional (la lengua, la historia, la referencia al territorio, las instituciones propias, etc.) que exigen una dimensión específicamente pública (una planificación educativa, una ordenación del territorio, una política de inmigración, etc.) que sólo puede realizarse adecuadamente como consecuencia del autogobierno (en su acepción más radical entienden que debe expresarse como la soberanía política propia de un Estado).

Por su parte, los grupos inmigrantes con conciencia identitaria, además de la no discriminación individual y del reconocimiento de sus derechos como ciudadanos, demandan también (y sobre todo) la no discriminación colectiva. Entienden que los estados nacionales, en los que viven y trabajan, se sustentan sobre múltiples rasgos culturales propios, enraizados en sus tradiciones, que son la base de su identidad nacional (la religión tradicional y dominante, una cierta institucionalización familiar, determinadas costumbres personales y sociales, etc.). Consideran también que estos rasgos son, de hecho, públicamente protegidos y fomentados (a través de políticas educativas, de subvenciones públicas, etc.) en detrimento de otras tradiciones. Interpretan esto como una discriminación "colectiva" hacia su religión, sus costumbres y tradiciones que están en la base de su propia identidad. Sin pretender enfrentarse a la cultura nacional, incluso aceptando que ésta tenga prevalencia pública (lengua e historia), piden que también su propia cultura sea protegida con su presencia en el ámbito público (derechos poliétnicos: escuela, calendarios festivos, etc.). ${ }^{23}$

\section{IDENTIDAD, DIVERSIDAD CULTURAL Y DERECHOS COLECTIVOS}

Kymlicka señala bien la ambigüedad que encierra el concepto de "derechos colectivos" (a los que prefiere denominar derechos diferenciados); sobre todo, porque sugiere una falsa dicotomía con la noción de derechos individuales. No cabe realizar una simplificación conceptual, ligándolos a una titularidad y ejercicio colectivo; nada impide que sean otorgados y ejercidos por los individuos de un grupo; lo esencial estriba en su fundamento: que se trate de derechos diferenciados en función del reconocimiento de la identidad nacional de un grupo. No se trata de resucitar el viejo debate filosófico político entre individualistas y colectivistas buscando una justificación a la primacía de la comunidad sobre el individuo: no es ése el nú-

${ }^{23}$ ETXeBarkíA, x., "Estado pluricultural”, op. cit., p. 143-144. 
cleo de la cuestión. Se trata de una cuestión de justicia entre grupos, cuyo respeto -incluso dentro del propio planteamiento liberal- exige reconocer derechos diferentes a quienes forman parte de grupos diferentes. ${ }^{24}$

La concepción "liberal”, en efecto, parte de que el origen de los derechos no está en la comunidad sino en el individuo; de ahí que encuentre el fundamento de los derechos colectivos en el derecho de todo individuo a mantener y expresar su identidad cultural, lingüística y religiosa. Es decir, también la tradición liberal más clásica (Manzini, Humboldt) entiende que la gestación de la individualidad y el desarrollo de la personalidad humana están íntimamente ligados a la pertenencia al propio grupo nacional, debido al importante papel que la lengua y la cultura juegan en la conformación de las opciones que cada sujeto elige. En ese sentido, una sociedad liberal, basada en la igualdad de consideración y respeto hacia las legítimas opciones de vida de todos sus miembros, no puede permitir que haya ciudadanos de primera (los de la cultura dominante, cuyas opciones son privilegiadas) y ciudadanos de segunda (los de las culturas minoritarias, relegadas a opciones marginales), sino que la justicia exige aceptar un presupuesto -la pluriculturalidad-y una consecuencia: arbitrar los procedimientos políticos necesarios para que exista una igualdad en la expresión de los diferentes modos de vida, originados en culturas diferentes. Por ello, aún desde una concepción individual de los derechos, el Estado nacional se ve abocado a la pluriculturalidad y obligado a conceder relevancia pública a determinadas manifestaciones colectivas de carácter identitario. La dificultad radica, naturalmente, a la hora de delimitar e identificar lo que entendemos por identidades culturales diferenciadas.

\subsection{La identidad cultural como presupuesto del ejercicio de las libertades}

El término "cultura", en sentido débil, alude a un conjunto de costumbres que pueden atribuirse a determinados grupos cuyo carácter puede ser étnico, de edad, clases sociales, tendencia sexual, etc. Pero, en sentido fuerte, suele aludir a un conjunto de pautas de pensamiento y de conducta, que dirigen las actividades y producciones materiales y mentales de un pueblo y que permiten diferenciarlo de los demás. La cultura incluye, pues, formas de conducta, reguladas por normas y sustentadas por valores que las legitiman y hacen comprensibles, y también prácticas legitimadas e

${ }^{24}$ KYMLıCKA, w., Ciudadanía multicultural, op. cit., pp. 71-76. 
institucionalizadas, siendo la lengua el vehículo esencial de identificación y la religión el mecanismo usual de legitimación. Kymlicka la denomina "cultura societal", e incluye en ella no sólo memoria y valores compartidos, sino también instituciones y prácticas comunes (vida social, educativa, recreativa, religiosa y económica, abarcando las esferas pública y privada). ${ }^{25}$ Cultura, en este sentido fuerte, vendría a identificarse como una cosmovisión, como un modo de concebir el sentido de la vida y de la muerte, que justifica la existencia de diferentes normas y valores morales. Se trata de una cosmovisión, más o menos perfilada, que una generación adulta quiere legar a sus descendientes; por eso las culturas son intergeneracionales. ${ }^{26}$

¿Cuál es la razón por la cual las identidades culturales colectivas deberían ser respetadas y jurídicamente protegidas? Esta razón no se encuentra en el valor intrínseco de cada una de ellas (no todas las manifestaciones de una cultura son respetables), ni en la presunción de que todas las culturas son igualmente valiosas (el relativismo cultural no es defendible). ${ }^{27}$ La razón se encuentra en que la identidad personal de cada individuo no es abstracta, es intersubjetiva y sólo puede aquilatarse en un contexto social y cultural de pertenencia. ${ }^{28}$ Las cosmovisiones o culturas societales suponen, en palabras de Dworkin, "un léxico compartido de tradición y convención”, lo cual significa que cada una de ellas proporciona al individuo el marco de libre elección de su proyecto vital (el conjunto de opciones posibles), pero además le proporciona las pautas (creencias) con las que puede enjuiciar el valor y la importancia de esas opciones. Como apunta Kymlicka, aquello que dota de sentido a la libertad individual es la participación en una cultura concreta, puesto que son las culturas las que nos ofrecen el contexto de elección que necesitamos (nadie elige en vacío o desde cero, se elige siempre con el trasfondo de un horizonte de posibilidades). Las culturas, pues, no son valiosas por sí mismas (frente a ciertas pretensiones comunitaristas), sino porque se muestran como condición de posibilidad de nuestra autorrealización. Dicho de otro modo: la capacidad de las personas de realizar elecciones significativas depende del acceso a una cultura societal.

\footnotetext{
${ }^{25}$ kYMLICKA, W., Ciudadanía multicultural, op. cit., p. 112.

${ }^{26}$ LAMO DE ESPINOSA, E., Culturas, estados, ciudadanos, op. cit., pp. 15-16.

${ }^{27}$ FERNÁNDEZ RUIZ-GÁlVEZ, E., Igualdad y derechos humanos, op. cit., pp. 181-183.

${ }^{28}$ MARTINEZ-PUJlate, A., "Derechos humanos e identidad cultural. Una posible conciliación entre interculturalidad y universalidad”, en Persona y Derecho, No. 38, 1998, pp. 120-127.
} 
Los vínculos de la lengua y la cultura son particularmente fuertes y persistentes, y aun cuando las personas pueden, por supuesto, trasladarse de una cultura a otra, eso es algo infrecuente y muy costoso que, como apunta Rawls, a nadie puede exigirse contra su voluntad. Ciertamente, las culturas liberales han ido perdiendo elementos diferenciales e incorporando elementos compartidos con otras culturas, pero ese fenómeno (globalización) ha ido parejo al crecimiento del sentimiento nacionalista y a la valoración de la propia identidad y pertenencia. Ello parece una consecuencia de que el respeto y la estima que cada persona siente sobre sí misma está estrechamente vinculado a la estima que merece su cultura nacional. ${ }^{29}$

Establecida la intrínseca vinculación de la identidad cultural con el ejercicio de la libertad, podría afirmarse el derecho a una cultura (forma de vida en común significativa para el sujeto) y se estaría legitimado para exigir sus condiciones de viabilidad en el ámbito público, no relegándolas a la esfera privada. Ese reconocimiento se concreta en la protección jurídica y en la atribución de la plenitud de la ciudadanía; esto es, en el reconocimiento de una identidad colectiva diferenciada, basada sobre el reconocimiento de derechos diferenciados. Como señala Amy Guttmann, el pleno reconocimiento de ciudadanos iguales puede requerir dos formas de respeto: a la identidad única de cada individuo, cualquiera que sea su sexo, raza o etnia, y a las concepciones del mundo que son objeto de un alto aprecio por los grupos a los que se encuentran estrechamente vinculados. ${ }^{30}$

Desde esta perspectiva, existen diferencias culturales que no pueden mantenerse y transmitirse contando sólo con la protección de los derechos civiles y políticos individuales. Los derechos colectivos funcionan entonces como "protecciones externas" para los grupos étnicos, porque impiden que las instituciones del grupo se vean atropelladas por las decisiones de la mayoría. Las protecciones externas son, pues, intergrupales, pero ¿qué sucede en el interior de los grupos étnicos? ¿Es tolerable que priven de autonomía a sus miembros? Kymlicka reconoce que los derechos colectivos tienen, sobre todo, dos límites: un grupo no puede escudarse en sus derechos como colectivo para oprimir a sus propios miembros, ni tampoco para dominar a otro grupo. Es decir, los grupos no pueden utilizar sus derechos como "restricciones internas", pretendiendo limitar la libertad de sus miembros para cuestionarse o apartarse de sus prácticas tradicionales.

\footnotetext{
${ }^{29}$ KYMLICKA, W., Ciudadanía multicultural, op. cit., pp. 122-133.

${ }^{30}$ GUtTMAnN, A., "Introducción", en TAYLOR, CH., El multiculturalismo y la política de reconocimiento, FCE, México, p. 21.
} 
Se trata, pues, de articular un complejo modelo convivencial que asegure la igualdad entre los grupos, y la libertad e igualdad dentro de los grupos. Algo que, como el propio Kymlicka reconoce, se sostiene bien en un planteamiento teórico, pero no resulta fácil en la práctica. ${ }^{31}$

La existencia de un derecho a la protección de las identidades culturales, como acertadamente señala Encarnación Fernández, comporta cuatro importantes presupuestos. Desde el punto de vista de su titularidad, se trata de un derecho humano individual y no de un derecho colectivo, aunque reviste la peculiaridad, como ya aclaraba Kimlycka, de que se ostenta en cuanto que se es miembro de una minoría cultural. Desde el punto de vista político y jurídico, carece de sentido esforzarse por mantener vivas aquellas culturas que ya no son relevantes ni significativas para nadie. La supervivencia de las culturas, como apunta Habermas, depende de la voluntad de los miembros de un grupo de querer mantener esa identidad. Desde el punto de vista contextual (intergrupal), subrayado especialmente por Touraine, igualdad y diversidad deben conciliarse desde la supremacía de la libertad del sujeto. Por último, desde la perspectiva de los límites de ese derecho, resulta exigible el respeto absoluto a la dignidad de la persona (aceptando las denominadas "protecciones externas" pero rechazando las "restricciones internas"). ${ }^{32}$

\section{2. ¿Cómo encajar el pluralismo moral derivado de la diversidad cultural?}

Kymlicka distingue tres formas de diversidad cultural con relevancia pública: la de los estados multinacionales (basada en la existencia de identidades nacionales y en la exigencia de autogobierno); la de los estados poliétnicos (basada en la existencia de etnias con cosmovisiones diversas que reivindican el derecho a mantener su cultura y su religión); y la de los grupos tradicionalmente desfavorecidos (mujeres, discapacitados, homosexuales, etc.). ${ }^{33}$ De estos tres tipos de diferencias culturales, en opinión de Adela Cortina, sólo el segundo grupo puede plantear problemas de acomo-

\footnotetext{
${ }^{31}$ Sin embargo, aun aceptando que no son admisibles las restricciones internas, Kymlicka entiende que no es lo mismo describir una teoría defendible de los derechos de los grupos que imponerla. En su opinión, es preferible que los liberales se acostumbren a convivir en sus países con grupos no liberales (por ejemplo, el pueblo indio), como lo hacen con grupos no liberales de otros países (KYmLıckA, W., Ciudadanía multicultural, op. cit., pp. 143-166).

32 FERNÁNDEZ RUIZ-GÁlVEZ, E., Igualdad y derechos humanos, op. cit., pp. 185-192.

${ }^{33}$ кYMLıcka, w., Ciudadanía multicultural, op. cit., pp. 46-55.
} 
dación de la pluriculturalidad desde el punto de vista moral. En el primer caso, las subunidades nacionales pueden compartir la misma cosmovisión, aunque se sientan naciones distintas. ${ }^{34}$ Por su parte, los grupos tradicionalmente desfavorecidos no reclaman una "ciudadanía diferenciada", sino medidas de discriminación positiva hasta ser tratados como iguales a los demás desde su diferencia. ${ }^{35}$ Sin embargo, las etnias con cosmovisiones distintas sí plantean, en principio, el problema de articular su convivencia con el resto de ciudadanos, porque su singularidad puede entrar en colisión con cuestiones de justicia. ${ }^{36}$

Si por "diversidad cultural" se entendiera sólo diversidad de costumbres (comida, vestido, entretenimiento), acomodar las diferencias culturales, aunque llevara tiempo hacerlo, no sería más difícil que acomodar cualquier otro tipo de diferencia grupal. El problema, como bien señala Cortina, se plantea cuando interaccionan distintas cosmovisiones y cuando esas cosmovisiones comportan concepciones de justicia que entran en conflicto. El liberalismo intenta resolver la cuestión del pluralismo moral encontrando unos mínimos de justicia entre las distintas doctrinas sobre la vida buena. ${ }^{37}$ Pero ¿qué sucede cuando existen discrepancias profundas entre culturas sobre cuestiones de mínimos de justicia? Por ejemplo, cuando una cultura entiende que la mujer carece de libertad para organizar su vida a diferencia del varón; o cuando una comunidad rechaza la educación pública para sus jóvenes, como es el caso de los amish, a los que algunos autores consideran "ciudadanos parciales", porque renuncian voluntariamente a derechos

\footnotetext{
${ }^{34}$ Es el caso de España, donde todas las comunidades autónomas se autocomprenden desde la cultura de la democracia liberal, que tiene en el trasfondo una raíz judía y cristiana. Comparten, pues, el sentido de la organización política, de las normas morales, incluso de la vida y la muerte. Lo que se reclama es construir de otra forma el mapa político y, en lo que se refiere a la lengua no hablada por el resto de España, derechos que arropen su mantenimiento y transmisión.

35 CORTINA, A., "Ciudadanía intercultural", en Glosario para una sociedad intercultural, op. cit., pp. 38-39.

${ }^{36}$ Si nos ceñimos al ejemplo de España, pueden presentarse problemas de convivencia entre una cultura democrático-liberal y las peculiaridades de la población gitana y musulmana. Dos ejemplos que destruyen la identificación de algunos autores entre minorías étnicas e inmigración: en nuestro caso, ni todos los grupos inmigrantes se identifican con una cultura distinta a la occidental -sólo los musulmanes-, ni la diversidad cultural se debe sólo a esos inmigrantes, sino también a indígenas tan acreditados como los gitanos. Importa puntualizar esto, porque la prensa suele unir "inmigración-multicuturalidad-delincuencia-trabajo" en una noche en que todos los gatos son pardos (CORTINA, A., "Ciudadanía intercultural", op. cit., p. 39).

${ }^{37}$ Estos mínimos, que son en parte actuales y en parte proyecto, pueden constituir una "concepción moral de la justicia, común a distintas doctrinas comprehensivas del bien" (RAwls, J., Liberalismo politico, Crítica, Barcelona, 1996) o bien una "ética mínima", compartida por las distintas "éticas de máximos" (CORTINA, A., Ciudadanos del mundo, Alianza, Madrid, 1997). En un caso y otro intentan que los ciudadanos de una comunidad puedan construir su vida juntos más allá de sus diferencias y peculiaridades.
} 
y responsabilidades ciudadanas; o cuando la comunidad asigna a algunos de sus miembros el derecho a juzgar y castigar, y se niega a aceptar la legitimidad de los jueces externos. ${ }^{38}$ ¿Qué propuestas se presentan hoy desde el liberalismo para organizar comunidades multiculturales de forma éticamente deseable y políticamente viable?

En primer lugar, aparece la propuesta del denominado "liberalismo intolerante", bastante difundido en Europa, abanderado por Giovanni Sartori, que recela de la entrada de inmigrantes fuertemente impregnados por una cultura autóctona no liberal (sobre todo musulmanes) por entender que suponen un peligro para las convicciones occidentales. Esta posición, obviando que quienes vienen en las pateras lo hacen urgidos por la miseria, se pone en guardia frente a culturas no liberales, recordando que el pluralismo es un valor fundamental de Occidente y aconsejando no tolerar la implantación de culturas no liberales. ${ }^{39}$ No parece que aporte una solución ni satisfactoria ni realista.

Una segunda propuesta viene planteada por A. Cortina, desde lo que denomina un "liberalismo radical-intercultural". Es un liberalismo radical porque entiende que la autonomía de las personas es irrenunciable, que deben elegir su propia vida y, por tanto, que las restricciones internas son intolerables. Los miembros de los diversos grupos culturales deben poder conocer ofertas diversas, ponderar cuáles son las que prefieren y elegir libremente, de modo que el grupo no restrinja su libertad..$^{40}$ Desde esa base,

\footnotetext{
${ }^{38}$ El famoso asunto del velo islámico será un problema de justicia si el velo expresa inferioridad de la mujer, no si se trata sólo de un símbolo religioso. Prohibir símbolos religiosos en lugares públicos, si no son expresivos de relaciones injustas, es propio de sociedades no pluralistas, sino confesional-laicistas, como la francesa. De hecho, los sikhs que deseaban ingresar en la Real Policía Montada del Canadá y no podían hacerlo porque su religión les prohibía prescindir del turbante, una vez reconocido el derecho a llevarlo, pudieron oficiar de policías (CORTINA, A., "Ciudadanía intercultural”, op. cit., p. 40).

${ }^{39}$ SARTORI, G., La sociedad multiétnica, op. cit., pp. 65-68. Como señala acertadamente Cortina, este recelo se tiene sólo frente al inmigrante pobre, frente al que los medios de comunicación presentan como un peligro, como fuente supuesta de delincuencia, competencia laboral e intransigencia cultural. Frente a estas expresiones en realidad de "aporofobia", más justo y eficaz sería que quienes, desde una cultura occidental, están convencidos del valor de la autonomía y los derechos humanos, traten de reforzar tales convicciones entre ellos con palabras y con hechos, en vez de insistir en que hay que debilitar los valores. Si lo hicieran así, se percatarian de que lo que urge es resolver el problema de la miseria, e integrar a los que huyen de ella, dialogar con su cultura y hacer creíble con la acción que el respeto a los derechos humanos es un buen programa ético-político (CORTINA, A., "Ciudadanía intercultural”, op. cit., p. 41).

${ }^{40}$ Porque bien puede ocurrir que quienes estén interesados en mantener las diferencias culturales sean los patriarcas y los líderes, más que los miembros. Sólo teniendo posibilidad de elegir es posible averiguar si una mujer prefiere aceptar el marido que otros le procuran, no trabajar fuera del hogar, vivir pendiente del varón. De ahí que no se pueda permitir en modo alguno que los grupos culturales coarten la libertad de sus miembros, de lo que sólo se beneficiarían los poderosos (CORTINA, A., "Ciudadanía intercultural", op. cit., p. 42).
} 
evitando el recurso a los derechos colectivos, aboga por establecer un "diálogo intercultural" que descansaría sobre dos presupuestos: el respeto a las culturas (porque los individuos se identifican y estiman desde ellas), y la posibilidad de que los ciudadanos puedan discernir qué valores y costumbres merece la pena reforzar y cuáles obviar. ${ }^{41}$ No son pocos los problemas que se suscitan a la hora de precisar el alcance de ese "respeto" y la identificación de las costumbres merecedoras de salvaguarda y promoción.

La tercera propuesta se ha denominado "liberalismo multiculturalista" y procede de Kymlicka quien, a diferencia de Adela Cortina, considera que los problemas de acomodación de cosmovisiones diferentes afectan fundamentalmente a las minorías nacionales, pero no a las minorías étnicas, que son fruto de la inmigración. En su opinión, toda cultura societal es una cultura nacional y toda nación es invariablemente una cultura societal. ${ }^{42}$ En el seno de las minorías nacionales es donde pueden albergarse prácticas no congruentes con los principios liberales de justicia (restricciones internas) que pretendan ser amparadas en función de la identidad cultural diferenciada, reconocida por un derecho colectivo (protecciones externas). Cuando eso se produce, Kymlicka piensa que el objetivo de las culturas liberales mayoritarias no debería ser disolver las culturas societales no liberales, sino más bien tratar de liberalizarlas, aun cuando esto no sea posible en todos los casos. No debería olvidarse, en su opinión, que todas las naciones liberales tuvieron pasados no liberales y que su liberalización exigió un prolongado proceso de reforma institucional. En consecuencia, como regla general, estima que no debería impedirse que naciones iliberales mantengan su cultura societal, sino que debería promoverse con todos los medios posibles su liberalización. ${ }^{43}$

¿Cómo puede y debe fomentarse ese objetivo? Para Kymlicka, hay que profundizar en el verdadero concepto liberal de tolerancia, siempre ligado a la autonomía. Hay que construir una correcta teoría de los derechos de las minorías sobre el respeto a los principios liberales de autonomía, libertad e igualdad. Pero hay que descartar el derecho automático de los liberales a imponer sus puntos de vista a las minorías no liberales. Las reformas liberales no deben basarse en la coerción sino en los incentivos; esto es, ventajas económicas, aceptación de acuerdos y tratados internacionales, etcétera. ${ }^{44}$

\footnotetext{
${ }^{41}$ CORTINA, A., "Ciudadanía intercultural”, op. cit., pp. 42-43.

${ }^{42}$ KYMLICKA, w., Ciudadanía multicultural, op. cit., p. 117.

43 Ibid., pp. 134-135.

${ }^{44}$ KYMLICKA, w., Ciudadanía multicultural, op. cit., pp. 211-237.
} 


\section{Pluriculturalidad y ciudadanía: propuestas de superación DEL MODELO LIBERAL}

La aceptación de la pluriculturalidad (multinacionalidad y polietnicidad) dentro de los estados exige una revisión de la teoría liberal clásica de la ciudadanía, en el intento de ir construyendo un nuevo concepto de ciudadanía pluricultural que se propone como alternativa al secesionismo y como presupuesto de un auténtico Estado pluricultural.

La ciudadanía es a la vez un concepto descriptivo, que identifica a quiénes se considera miembros de pleno derecho de una comunidad política, y un concepto normativo, que contiene las dimensiones de lo que debería ser un verdadero ciudadano. Atendiendo a la tradición liberal y republicana, el ciudadano es sujeto de derechos civiles y políticos (lo que tiene su raíz en el polites griego y en el civis latino); pero también de derechos económicos, sociales y culturales, como reconoce el concepto de ciudadanía social, acuñado por Marshall a mediados del siglo xx y que es hoy el concepto canónico. El ciudadano es -o debería ser- su propio señor junto a sus iguales en la comunidad política. Para lo cual, como recuerda Adela Cortina, es necesario añadir a las dimensiones civil, política y social, al menos otras dos: la económica (ha de participar en las decisiones sobre qué se produce, qué se consume, para qué y quiénes lo hacen) y la cultural, es decir, las instituciones y el ethos de la comunidad han de garantizar que los ciudadanos de distintas culturas sean tratados con igual consideración y respeto. Sobre esta última exigencia hay que plantear la construcción del Estado pluricultural, cimentado sobre la noción de una ciudadanía pluricultural..$^{45}$

Se pueden reconocer dos propuestas fundamentales en la construcción teórica de un modelo de Estado pluricultural, superador del Estado nacional: una propuesta "débil", basada en un concepto de ciudadanía que no pivote sobre la identidad nacional; y otra propuesta "fuerte", basada en la componente nacional y en la articulación de una auténtica ciudadanía diferenciada.

${ }^{45}$ CORTINA, A., "Ciudadanía intercultural”, op. cit., p. 36. 


\subsection{Pluriculturalidad y ciudadanía cosmopolita}

La primera de las propuestas tiene por fundamento lo que Habermas, recogiendo la propuesta de Adorno, denomina "patriotismo constitucional”. Habermas actualiza la solución liberal-republicana, manteniendo el principio de una ciudadanía uniforme pero disociada radicalmente de la nacionalidad. Plantea una "ciudadanía posmoderna o cosmopolita" en la que se mantiene la integración política, pero reducida a su aspecto puramente jurídico. De manera sintética viene a decir lo siguiente: hay que desligar lo que está unido en el Estado nacional, separar la cultura política común (la que remite a los derechos humanos) de la cultura nacional mayoritaria (identidad). La primera no puede ser expresión de una particularidad nacional (tener sentido excluyente), sino que debe expresarse como lealtad a un conjunto de principios y procedimientos democráticos que animan las instituciones y que están plasmados en la constitución (tiene sentido inclusivo y abierto). Con este presupuesto, la cultura mayoritaria nacional pasa a ser una subcultura entre las diversas subculturas presentes (por ejemplo, las de los colectivos inmigrantes o las de las minorías nacionales). Su existencia -y la del resto- estaría siempre protegida por los principios constitucionales. Pero esa protección no se plasmaría a través del reconocimiento de un inexistente derecho colectivo a la propia identidad; se aseguraría garantizando constitucionalmente la coexistencia igualitaria de formas de vida diferentes, cuyo único punto de unión sería el respeto a la cultura política común. Cada una de esas formas de vida evolucionará en función de las adhesiones libres, críticas y creativas de los ciudadanos, o de su rechazo igualmente libre. Los estados así definidos serán de este modo posnacionales; y el "patriotismo constitucional" expresa la integración política común que une a los ciudadanos. Todo individuo que se encuentre en un estado de derecho, cualquiera que sea, debe adherirse a un sistema determinado de valores y principios. Se trata, pues, de un patriotismo abstracto, referido a procesos y principios abstractos. ${ }^{46}$

Este pretendido reconocimiento igualitario de todas las culturas particulares, sustentado sobre el respeto a los derechos humanos, resulta teóricamente muy atractivo, pero parece difícilmente aplicable en las actuales

\footnotetext{
${ }^{46}$ HABERMAS, J., Identidades nacionales y posnacionales, Tecnos, Madrid, 1989, p. 238. Vid. también, HABERMAS, J., La inclusión del otro. Estudios de teoría política, Paidós, Barcelona, 1999; HABERMAS, J., La constelación posnacional. Ensayos políticos, Paidós, Barcelona, 2000.
} 
condiciones de la humanidad. Se han señalado acertadamente cuatro ángulos problemáticos en la propuesta.

En primer lugar, parece presuponer la existencia de un procedimentalismo justo que podría universalizarse por encima de las particularidades propias de cada cultura. Pero el mismo Habermas reconoce que las producciones humanas no funcionan así. Afirma que el patriotismo constitucional aparece siempre éticamente (étnicamente) modelado, siendo expresión de una particular forma de vida y no mero reflejo del universalismo de los derechos. Bastaría, pues, con que este "modelado" tuviera una cierta relevancia para que la distinción entre cultura política común y cultura nacional mayoritaria resultara muy debilitada. ${ }^{47}$

En segundo lugar, desde el presupuesto de la igualación de las culturas, se hace difícil de justificar una política de control de la inmigración (por ejemplo, en forma de cupos), que el propio Habermas acepta. Los principios de la cultura política común impedirían privilegiar a un inmigrante andaluz que quiere ir a Madrid sobre un inmigrante marroquí que también lo quiere. La exclusión de la nacionalidad del ámbito público reclamaría iguales derechos de inmigración para todos en todas partes y no parece que esto sea un planteamiento realista en el actual contexto internacional. ${ }^{48}$

En tercer lugar, las fronteras de los estados, construidas con criterios de nacionalidad, dejarían de tener sentido. En efecto, carecería de sentido que una minoría nacional reivindicara la soberanía política, pero también carecería de sentido que esa soberanía sea reivindicada por los actuales estados que se sustentan sobre las mayorías nacionales presentes en ellos. Habermas lo tiene de algún modo presente cuando subraya la arbitrariedad de las actuales fronteras y pide que se avance hacia federaciones de estados (como en el caso europeo). ${ }^{49}$ Pero no podemos olvidar que estas federaciones se sustentan también sobre una cultura particular compartida por los estados que las forman (cabría considerar la Federación como un Estado plurinacional); por ello, la lógica de la propuesta de Habermas apunta hacia la construcción de un Estado mundial; pero tal pretensión, hoy día, resulta extremadamente problemática. ${ }^{50}$

En cuarto lugar, la propuesta no permite aclarar qué aspectos de las culturas coexistentes requieren una manifestación igualitaria en el ám-

\footnotetext{
${ }^{47}$ etXebarría, x., "Estado pluricultural”, op. cit., p. 145.

${ }^{48}$ Idem.

${ }^{49}$ Habermas, J., La constelación posnacional. Ensayos politicos, op. cit., pp. 121-124.

${ }^{50}$ etXebarkía, X., "Estado pluricultural”, op. cit., p. 145.
} 
bito público y qué tipo de protección se les debe otorgar. Por ejemplo: ¿en qué lengua o lenguas se debe hablar en la Administración pública o enseñar en las escuelas? ¿Qué calendario festivo debe regir en el Estado? ¿Qué relatos históricos deben ser enseñados? ¿Qué organización territorial debe implantarse?, etc. En las actuales condiciones parece inevitable que las culturas nacionales tengan una cierta preferencia en estos ámbitos (es difícil pensar que en las escuelas públicas de un Estado que seguimos llamando "alemán" la cultura turca o italiana -o la de otros grupos inmigrantes significativos- deban tener la misma relevancia que la cultura alemana, siempre que así lo reclamen). De igual modo, resulta muy difícil imaginar una escuela en la que no haya más referencia que la cultura política común. En definitiva, no parece verosímil la separación entre culturas nacionales y políticas públicas de protección específica. ${ }^{51}$

Más allá de las dificultades señaladas, la propuesta de Habermas contiene un elemento indispensable en la gestión política de la pluriculturalidad: el presupuesto irrenunciable de la igualdad y del respeto a todos los seres humanos en su condición de tales. Sin embargo, la modulación cultural de dicho reconocimiento parece indispensable. Como ha puesto de relieve Schnapper, la identidad política implica un lazo afectivo con la cultura y valores de una sociedad concreta. Por ello, plantea la necesidad de salvaguardar al mismo tiempo "el valor de la dignidad del individuo, consagrado por la ciudadanía, y la necesidad que tiene este individuo-ciudadano de ser plenamente reconocido en la autenticidad de su cultura". ${ }^{2}$

\subsection{Pluriculturalidad y ciudadanía diferenciada}

La importancia de concebir una ciudadanía no disociada de la nacionalidad y modulada en función del pluralismo cultural, ha sido desarrollada por Charles Taylor y, fundamentalmente, por Will Kymlicka, que ha dado sus credenciales al concepto de "ciudadanía diferenciada". Se trataría de plantear una nueva organización política y social que podría denominarse, en sentido estricto, un "Estado pluricultural", capaz de conciliar la igualdad de los ciudadanos y la libertad de los individuos, propias de toda sociedad democrática, con el reconocimiento institucional de las especificidades culturales.

${ }^{51}$ Ibid., p. 146.

52 SCHNAPPER, D., La relation à l'Autre, Gallimard, Paris, 1998, p. 481-482. 
La propuesta de Kymlicka, al igual que la de Taylor, ${ }^{53}$ da carta de naturaleza plena a la existencia de "derechos colectivos" (diferenciados). Su planteamiento teórico parte del presupuesto liberal y universalizable de la autonomía individual como valor de referencia indiscutible. Sin embargo, para Kymlicka, las "culturas nacionales" son las más significativas para la mayoría de los individuos; son el contexto de expresión auténtica de las libertades individuales y, por ello, precisan un nivel de autogobierno relevante para mantenerse. En consecuencia, resulta coherente afirmar la existencia de un derecho colectivo a preservar las culturas nacionales y a su correspondiente autogobierno desde el que se protegen y desarrollan. ${ }^{54}$

Con este sustrato teórico, Kymlicka preconiza un reconocimiento público de las diversas identidades culturales bajo dos condiciones, no fáciles de garantizar: a) que la sociedad no degenere en un estallido de entidades yuxtapuestas y cerradas; b) que no reprima la libertad del individuo obligándolo a formar parte de un grupo determinado. Salvaguardadas esas dos precauciones, la ciudadanía deja de ser "común" y se convierte en "diferenciada" a través de los derechos colectivos, que varían en función de la "naturaleza" de las colectividades concernidas: derechos de autogobierno para las comunidades nacionales (núcleo de la ciudadanía diferenciada) y derechos poliétnicos y de representación para los grupos étnicos.

Kymlicka propone abordar sin reparos la secesión como una opción válida para las minorías nacionales y no como una catástrofe que debe evitarse siempre. No obstante, reconoce que facilitar a cada nación que se constituya en Estado nacional resultaría muchas veces imposible y muchas otras no deseable o excesivamente traumático (hay más naciones que estados posibles); por ello apuesta por mantener la unidad constituyendo estados federales, en el sentido fuerte del término, con un carácter inequívocamente multinacional. Se trataría de un acuerdo federal (mediador entre los extremos del secesionismo de las diversas naciones y del asimilacionismo de la nación mayoritaria) que, por un lado, reconociera

\footnotetext{
${ }_{53}$ Taylor parte de la complejidad de las identidades y apuntala el doble presupuesto liberal y multicultural afirmando que "una sociedad verdaderamente libre es una sociedad donde las identidades complejas puedan dilatarse. Esto significa, por una parte, que la identidad política no trate de reprimir la diferencia y limitar su presencia en el espacio público y, por otra parte, que las comunidades particulares no intenten monopolizar la vida de sus miembros". El modelo político para consagrar la diferencia puede revestir formas variadas: federalismo, regionalización, descentralización, autonomía local, etc. "Es tiempo -afirma- de reconocer que pueden existir diversas maneras de integrarse a la totalidad." En su opinión, las identidades complejas pueden reforzar el compromiso político y la vida democrática (TAYLOR, cH., Argumentos filosóficos, Paidós, Barcelona, 1999, p. 27 y ss).

${ }^{54}$ KYMLıCKA, w., Ciudadanía multicultural, op. cit., pp. 112-133.
} 
un importante grado de autogobierno a las subunidades nacionales y, por otro, reconociera que la federación es un pacto entre grupos nacionales iguales, por tanto revocable, en condiciones que deben ser también pactadas. Las bases de la unidad social y política en el Estado multinacional provendrían de lo que denomina "identidad compartida" o conciencia de que el gobierno general del Estado es el contexto en el que se reafirma cada identidad y no al que se subordina. Este concepto habría que completarlo con el de "diversidad profunda" propuesto por Taylor, para permitir acomodar no sólo culturas diversas sino también maneras diversas de vinculación al Estado de los miembros de esas culturas en función de su concepción del Estado. ${ }^{55}$

El propio Kymlicka admite la enorme dificultad práctica de este modelo, no sólo a la hora de conseguir el consenso político por parte de todos, sino a la hora de establecer un marco territorial para las naciones. Los sentimientos identitarios, en efecto, no suelen tener fronteras precisas y hacen muy difícil su delimitación espacial, en particular, en países como Canadá o España, en los que subunidades de base nacional se mezclan con subunidades de base territorial (lo que dio lugar en su momento a la polémica propuesta de un federalismo asimétrico). No obstante, a pesar de las dificultades, el acuerdo federal se presenta como el modelo político más acorde con el respeto a la pluriculturalidad nacional y a la autonomía de los individuos.

Esta propuesta de ciudadanía diferenciada presenta una peculiaridad que ya hemos apuntado: defiende la importancia y relevancia de las "culturas nacionales" pero no considera tan significativa la pluriculturalidad originada por la inmigración, para la que asume de facto la propuesta de Habermas, planteando una integración de los inmigrantes en la "cultura política común” y estableciendo los mecanismos de protección para las especificidades culturales. ${ }^{56}$ Algunos consideran que una distinción tan marcada entre minorías nacionales y colectivos inmigrantes no parece muy razonable si se quiere afrontar una verdadera gestión de la pluri-

\footnotetext{
${ }^{55}$ Ibid., pp. 248-263.

${ }^{56}$ No obstante, el modo concreto en que Kymlicka plantea esa integración parece ir algo más allá de los "principios abstractos" del patriotismo constitucional, solicitando también su integración en las instituciones propias de las culturas nacionales, acordes siempre con los planteamientos democráticos y liberales. Junto a esto plantea también la asunción por parte del país receptor de determinados aportes de la cultura inmigrante, de modo tal que cuando los inmigrantes se integren en ella lo hagan no en algo absolutamente ajeno, sino en algo ya enriquecido por ellos (KYMLICKA, W., Ciudadanía multicultural, op. cit., pp. 242-248).
} 
culturalidad, ya que la integración política que se exige a éstos es excesivamente nacional y "fuerte" y que el reconocimiento y protección de las especificidades culturales de los colectivos inmigrantes frente a los nacionales es muy "débil". ${ }^{57}$ Ciertamente, la propuesta presenta evidentes zonas de discusión; sin embargo, y por el momento, constituye la única base para la superación del Estado nacional y la construcción del Estado pluricultural.

\section{Algunas conclusiones}

A la luz de lo expuesto, cabría constatar tres afirmaciones relevantes en la problemática gestión de la pluriculturalidad en las sociedades modernas basadas en la estructura del Estado nacional:

a) Aunque no haya que considerar, por principio, que la secesión es siempre un fenómeno indeseable y traumático, consecuencia perversa del nacionalismo, tras la desintegración de la ex uRss y la ex Yugoslavia, parecía existir en Europa una imposibilidad práctica y política de poner en marcha un proceso jurídico reglado que pudiera desembocar pacíficamente en la secesión y en la creación de un nuevo Estado nacional. La reciente experiencia de la declaración de independencia de Kosovo, votada por su parlamento el 16 de febrero de 2008 y reconocida por diversos países europeos (además de Estados Unidos), ha desmentido este tácito principio. En la medida en que vaya siendo reconocido internacionalmente, se consolidará su situación, demostrando que también hoy es posible la secesión siempre que exista una comunidad nacional identitaria lo bastante fuerte como para llevarla a cabo y una comunidad internacional lo bastante débil como para permitirlo.

b) Las identidades nacionales, expresión de las diversas identidades culturales, tienen pleno sentido, arraigo y vigor en la era de la globalización, en cuanto que no son, en absoluto, una amenaza a la universalidad de los derechos, sino que, por el contrario, son el presupuesto de un ejercicio significativo de las libertades individuales. La capacidad de las personas de realizar elecciones significativas depende de su pertenencia a una cultura nacional. Puede afirmarse, pues, la existencia de un derecho individual a la identidad cultural (protección institucional de formas específicas de vida en común), como exigencia intrínseca de la identidad personal. Su

${ }^{57}$ Vid. etXebarkía, x., "Estado pluricultural”, op. cit., p. 146-147. 
articulación política en clave de derechos colectivos o diferenciados, debe entenderse desde la atribución de su titularidad en función de la pertenencia a un grupo nacional o étnico.

c) El reconocimiento pleno de la pluriculturalidad exige una nueva articulación del Estado, como multinacional y poliétnico. La respuesta del cosmopolitismo resulta excesivamente teórica y débil. La apuesta por el reconocimiento de una ciudadanía diferenciada, presenta diversos niveles según la "naturaleza" nacional o étnica (originaria o sobrevenida) de los grupos presentes en el Estado. La propuesta de Kymlicka, federalista (y consensual) para las comunidades nacionales originarias e integracionista (y diferenciada) para los grupos étnicos de inmigración sobrevenida, no parece responder del todo al desafío que presenta en Europa, por ejemplo, la masiva inmigración de marcado carácter islámico. 